\title{
Justice, feasibility, and social science as it is ${ }^{1}$
}

Political philosophers often make proposals that appear to lie beyond our reach, such as open borders, global egalitarianism, market socialism, or the end of all forms of hierarchy. However, some object that this way of conducting political philosophy strays too far from facts about what humans or societies are - or even could be - like. Hence, recently much has been written about whether, instead, claims about justice ought to be constrained by what we are able to bring about or could realise: by considerations of feasibility. Some argue that if a proposal is not feasible, then it is not one we ought to aim at nor even one that could count as a demand of justice. ${ }^{2}$

How should political philosophers respond to the challenge of a feasibility constraint and its promise as a useful criteria for theory choice? Generally, the debate has been on a conceptual level, over the nature of justice as a concept and whether it is essentially action-guiding, or over whether the kind of 'oughts' found in theorising about justice imply 'feasible' (e.g. Gheaus 2013, esp. p. 445; Southwood 2016; Wiens 2014). Very often, these discussions rely on claims about the ultimate or fundamental purpose of political philosophy. For instance, should political philosophy construct visions of an ideal society we can never get to, or tell us what to do from here (e.g. Estlund 2014; Gheaus 2013; Wiens 2014)? However, I take a different approach to the debate over the feasibility

\footnotetext{
${ }^{1}$ Research for this article was was completed under the ARC project DP120101507 on 'Political Normativity and the Feasibility Requirement'. With thanks to Nic Southwood, Saladin Meckled-Garcia, Christopher Nathan, Albert Weale, Jeff Howard, and two anonymous referees for this journal for their written comments, and to audiences at the PPE seminar, Institute of Philosophy; Senior seminar, Philosophy Department, University of Glasgow; 10th Legal and Political Theory conference, Manchester; the Open University "Philosophy day"; and the 'Cherry Pickers' workshop at UCL, for all their useful questions.

${ }^{2}$ A taxonomy of different approaches is offered in Southwood \& Wiens 2016: 6, fn 12. For examples, see Gilabert 2017; Gilabert \& Lawford-Smith 2012; Hamlin 2017; Lawford-Smith 2013; Miller 2013 Southwood 2016; Wiens 2015. Against, see e.g. Cohen 2005: 244-5; Estlund 2011, 2014: 130; Gheaus 2013. See also the broader ideal/non ideal theory debate e.g., Valentini 2012.
} 
requirement. Rather than engaging in the conceptual debate or defending some single purpose for political philosophy, I propose that we instead search for the facts that could fill out a feasibility requirement. Once we do so, and if due attention is paid to the nature of the social sciences, then the feasibility constraint turns out to be redundant, practically speaking, for political philosophers. It simply will not help pick between theories, neither ruling some out, nor counting in favour of others. To reject this scepticism would require adopting controversial and improbable commitments within the philosophy of social science. Further, this challenge to the usefulness of a feasibility constraint affects not only abstract ideal proposals like global egalitarianism or the difference principle but, rather, applies to near all non-ideal proposals too. ${ }^{3}$

The search for relevant facts can be motivated without appeal to my sceptical conclusion. For a start, without some indication of what facts would fill out a feasibility constraint, arbitrating between competing sides of the debate is hard. In particular, one popular strategy is appealing to the implications of taking one or other side. Those against a feasibility requirement declare that including facts would be excessively conservative or have a 'dampening effect' (e.g. Estlund 2014: 113). For instance, since people currently demand unequalising incentives, we would assume such inequality would always be required when assessing a proposal's feasibility. In contrast, those in favour of a feasibility requirement claim that it provides us with a useful way to choose between theories. ${ }^{4}$ Yet, without some relevant facts in view, neither sides' claims are substantiated: a feasibility requirement might be informative, or might be conservative, but that entirely depends on the facts in question.

Second, the feasibility constraint is often presented as if it has important implications for po-

\footnotetext{
${ }^{3}$ There is a parallel between this and the charge that contextualism in political theory is empty unless we know what the relevant context is. With thanks to a referee for this observation.

${ }^{4}$ Such claims are found in many introductions, e.g. Gilabert 2017, on radical egalitarianism; Southwood 2016, on 'Pecunia'. See also Anca Gheaus on which proposals are accused of infeasibility (2013: 452-3).
} 
litical philosophy, especially for what is termed 'ideal' political philosophy, including ruling out proposals like socialist utopias or open borders. ${ }^{5}$ Further, imposing a feasibility constraint would, I presume, radically alter how political philosophy was conducted, demanding far closer engagement with empirical research than is customary in order to demonstrate that one's proposals pass that test. If, in contrast, the feasibility constraint is not informative in this sense of counting against or ruling out some of the kinds of proposals political philosophers make, why care about it? Then, it would then make no difference to how to do political philosophy, nor what we propose. Thus, we have reason to go in search of the facts, to check there are some of the right kind about — those that would fill out a feasibility constraint. Once we do, however, this article's sceptical challenge results.

To clarify this article's target before the argument begins, I address a feasibility constraint as a way to choose between proposals of political philosophy, and so a particular role for facts as acting as independent arbitrators amongst competing proposals. In its strongest form, the claim in question is that meeting the feasibility constraint is a requirement, ruling out those proposals that fail its test. In its weakest form, the claim is that a proposal being feasible, or more likely to be feasible than others, provides a point in favour of that proposal. As such, this article is not aimed at the realist challenge to mainstream political philosophy as a whole, nor the non-ideal/ ideal theory debate but, rather, a particular but popular way to conceptualise how facts enter political philosophy. I use the term 'proposal' to cover principles of justice, conceptions of justice, and suggestions of particular features of societies, including both ideal and non-ideal proposals. I use the term 'feasible' to refer to a degree of difficulty in implementing some proposal, given the facts, where that includes considering both its accessibility and stability. Depending on one's specification of feasibility, those facts might be about how the world is or could be, how people are or could be, or what lies within the relevant agents' option sets.

\section{Finding facts in social science}

I begin by justifying a crucial assumption of following argument: the social sciences would be the place to find relevant facts for a feasibility constraint, should one desire informative facts ruling out or

\footnotetext{
${ }^{5}$ See fn. 3. Southwood \& Wiens (2016), defenders of a feasibility constraint, also require this informativeness.
} 
counting against some of the claims political philosophers make or, at least, some of the kinds of proposals made. Here, 'social science' is interpreted inclusively, to encompass psychology, economics, political science, history, sociology, anthropology, amongst other disciplines concerned with the social. Social sciences cover the realm within which political philosophers might make incorrect assumptions, including social organisation, the economy, and how people interact. In contrast, political philosophers do not tend to offer theories violating findings of physics, biology or chemistry. As Estlund comments: 'disputes about whether political philosophy properly respects human nature are not normally about issues like our need for oxygen or our tendency to age. What political philosopher puts these aside?' (2011: 209). ${ }^{6}$

Objecting, some might think that biology is more informative for political philosophers than I suppose. One potentially compelling example is that only those with wombs can bear children, which Susan Moller Okin (1989) uses to suggest that Nozick's libertarianism would result in a matriarchal slave-owning dystopia. However, first, Okin's point is that sometimes political philosophers forget that not all persons are male and consequently propose undesirable or absurd societies, rather than that biology is a helpful science to address feasibility. Second, this example is an outlier: very seldom do debates come down to facts like these. ${ }^{7}$

Others might protest that merely reflecting on the nature of people and society would result in

\footnotetext{
${ }^{6}$ This rules out one possible characterisation of a feasibility constraint as logical or nomological possibility (Gilabert \& Lawford-Smith 2012). For reasons detailed in section 2, that would exclude findings of social science. But this feasibility constraint would also fail to be informative, since philosophers do not break laws of logic or natural science: Wiens and Southwood dismiss it as 'ultra thin' (2016). Regardless, Gilabert and Lawford-Smith do not seem to intend this as a feasibility requirement's sole content even for ideal proposals depending on their notion of institutional design, where 'soft constraints' are relevant. This is clearer in Gilabert (2017), with his claims that failure at the point of implementation should inform ideals.

${ }^{7}$ Some might appeal to sociobiology, with its promise of informative constraints from, say, the inevitability of distinct sex roles. Yet, even aside from such claims being largely discredited (see Kitcher 2001, ch. 8), these purported facts share enough features of social sciences to apply the following arguments.
} 
many relevant facts. ${ }^{8}$ We could discover that we need food and can reproduce, or take David Miller's example that we make self-conscious choices and if we did not, liberty would lack intrinsic value (2013: 23). Surely, one might think, such common sense facts are relevant, in that no imagined society should fail to accommodate them?

Yet these common sense facts fail to be genuinely informative. Common contenders for being ruled out by the facts - open borders, global socialism, and the like - do not fall prey to this kind of very basic fact about humans: facts easily observed and where simple observation alone is evidence enough. Nor do these facts succeed in ruling out or counting against any of the kinds of theories that philosophers propose. Perhaps charitably, here I assume that political philosophers do not make such obvious mistakes: none, for instance, propose societies where human beings can live on air. Hence, even if, agreeing with Miller (2013) you hold that common sense facts ground ultimate principles, it does not follow that such facts count as informative when assessing feasibility in this article's sense.

At this point, some might attack my assumption that political philosophers possess common sense as being overly optimistic. For instance, one apparent fact easily accessible by reflection is that incentives are needed to motivate people to choose socially productive jobs, such that one cannot have a productive society without these. Similarly, some may insist that we can simply tell that open borders and global socialism are infeasible.

However, unlike basic facts about the kinds of being we are, such as that we need food, claims about the immutability of features of society require empirical grounding beyond our own observation. We can easily mistake features of our own society as being more fixed than they are, for instance, taking economic incentives as essential because we live under capitalism. Indeed, we may be inclined towards making such mistakes, given our bias towards defending the status quo: the

\footnotetext{
${ }^{8}$ Such a reliance on common sense may be implicit where those discussing feasibility requirements suggest proposals to be ruled out without empirical evidence: for examples, see fn 3 . So, too, many formulate feasibility constraints in terms of what lies within an agent's option set (e.g. Lawford-Smith 2013; Southwood \& Wiens 2016; Gilabert 2017). For individuals, determining the option set is often possible by looking, but that doesn't scale up to the more complex issue of a state's option set.
} 
system justification bias or just world hypothesis. People desire to believe the world is fundamentally just, and to do that, they may regard some otherwise unjustifiable injustice as deserved by the person suffering it, and adopt beliefs supporting the idea that the status quo is fair. ${ }^{9}$ Precisely these beliefs may be put forwards when making generalisations from features of our society to what is feasible including the need for incentives.

Regardless of this tendency to be mistaken, for 'common sense' claims to feed into our feasibility assessments we also need to know how enduring are these features of society, which takes us beyond common sense judgements. Unlike very basic facts about what kind of beings we are, features of our society claimed to be fixed can change. As Holly Lawford-Smith observes, often people have wrongly taken features of their own societies as fixed even where change was imminent; including the impossibility of votes for women and the end of slavery $(2013: 243){ }^{10}$

A final defence of common sense finds space between the blindingly obvious common sense judgements political philosophers do not violate and those common sense judgements reflecting blinkered views inherited from living within particular societies. One set of facts in that space concern the nature of large modern societies of the sort that David Miller (2013) and some political realists consider. ${ }^{11}$ For example, modern societies are characterised by pluralism, participate in global trade relationships, and face threats to order and security. A second set of facts address which proposals impose undue costs for creatures like us. ${ }^{12}$ Suppose that, for instance, fair equality of opportunity would be best realised by taking children from their parents, but parents would by nature find that unduly personally costly.

However, the above middle ground facts can be interpreted in two ways, neither of which undermines the arguments to follow. However, spelling these out helps us to clarify the nature of a

\footnotetext{
${ }^{9}$ On benevolent sexism playing this role, see Connell \& Heesacker 2012.

${ }^{10}$ For a challenge to taking what was achieved to tell us what was feasible, see Southwood \& Wiens 2016.

${ }^{11}$ On interpretations of political realism, see Rossi \& Sleat 2014.

${ }^{12}$ For the undue costliness characterisation, see Southwood \& Wiens 2016, with an example of Miller 2013.
} 
feasibility requirement. ${ }^{13}$ On the first interpretation, the appeals to facts above are not about feasibility but something else. Sometimes, appeals to pluralism or to threats to order are about the appropriate subject matter of political philosophy, for instance, that it must concern 'real politics'. ${ }^{14}$ Alternatively, as Laura Valentini (2012: 659) observes, such appeals can amount to claims that justice ought to be balanced against other values, such as stability. Similarly, appeals to undue costs can concern how competing values should be weighed or what trade-offs amongst values are permissible; for instance, when comparing equal opportunity to the value of the parental bond. But that is a normative matter. Neither claims about value trade-offs nor about the proper subject matter of political philosophy are this article's subject — rather, I address the idea that facts might play some independent role in choosing between theories: counting in favour of some proposals or ruling others out.

On the second interpretation, these middle-ground common sense facts do concern what we can bring about and, hence, are relevant for feasibility assessments. We are less likely to realise a proposal with undue costs, perhaps because we cannot bring ourselves to bring it about. ${ }^{15}$ For instance, parents might be unable to bring themselves to give up children for communal rearing in order to ensure equal opportunity, rendering that proposal infeasible, and claims about order might concern the the limits to feasible social organisation. Yet on this second interpretation common sense should be supported by empirical research. In particular, to know which undue costs block us from realising some goal progressively, over time, we'd need to find features of our psychology that pose lasting obstacles to our bearing certain costs, persisting across different forms of social organisation, or else limits to institutional design. Such matters are better answered by social science than from the armchair. Thus, there is no good alternative to social science to fill out a feasibility constraint. While some may have found this claim uncontroversial, despite the un-evidenced examples common in the

\footnotetext{
${ }^{13}$ With thanks to a referee for this observation.

${ }^{14}$ E.g. Rossi \& Sleat 2014. Estlund responds that if the facts of politics are such that some political philosophers fail to discuss politics, that doesn't matter — we still may be discussing justice (2014: 130-131).

${ }^{15}$ For this language of bringing oneself to x, see Estlund 2011; Southwood 2015.
} 
existing literature on feasibility, this article is devoted to showing that its implications are not.

\section{Describing the facts}

To begin the skeptical argument, I first ask, what, then, are the findings of social science like? What follows is a brief sketch of commonplaces within the philosophy of social science. ${ }^{16}$ Social science lacks laws of nature, at least of the kind found in physics. Fundamental physics discovers universal, exception-less regularities that are, in some sense, non-accidental. Of course, this being philosophy, each of these features is disputed (e.g. Cartwright 1999). Regardless, the regularities of social science are taken to be very different to the law-like regularities of physics.

In particular, even those who hold that social science should look for regularities accept that its regularities are more context-specific, 'exception-ridden' and imprecise than those of physics (e.g. Gorton 2016) ${ }^{17}$ The sensitivity to background conditions and lack of robustness of social sciences' regularities is of a different order to physics: these regularities sometimes operate but not always and often we cannot say when (e.g. Elster 1998, 2007). That is not to claim that social science has no generalisations to offer, nor that only its findings are subject to uncertainty. Instead, the claim is that social science's generalisations are of the form, 'if P, then sometimes Q', in Jon Elster's terms (1998). One clear indication of these features is the lack of predictive success of social sciences compared to physics with its apparently universal precise regularities. ${ }^{18}$ Elster attributes this lack to the fact that while the mechanisms of the social sciences help us to explain after the fact, we do not know in advance which mechanisms will operate (1998). Another indication is that the findings of social sciences tend to concern particular contexts, say, individual countries or kinds of economies.

\footnotetext{
16 The kinds of claims found in introductions, e.g. Cartwright \& Montuschi 2014, Elster 2007; Gorton 2016; Martin \& McIntyre 1994; Rosenberg 2015: ch. 1.

${ }^{17}$ As Rosenburg (2015) observes, some deny that we should focus on causal mechanisms, emphasising instead making the social world 'intelligible'. I focus on social science that yields regularities or generalisations since that has the best chance of filling out a feasibility requirement.

${ }^{18}$ Even those defending its predictive power regard it as very limited e.g. Reiss 2007.
} 
Indeed, many argue that social science not only is different but ought to be given its subject matter. We should not expect a science of the social sphere to resemble one of the physical world. ${ }^{19}$ For instance, Charles Tilly suggests that to think that there were law-like regularities to be found in political science requires holding that 'all political processes result from extremely general propensities in human nature' $(2001: 25)$. Others claim that there are far too many variables in the real world cases of concern to social scientists for them to make predictions or isolate regularities akin to those of physics. Some attribute this to an inability to create closed systems that would control for such variables (e.g. Lawson 1997: 35; Machlup 1961).

Some might resist the above claims of difference. First, some might claim that economics is special in discovering laws or, at least, more law-like regularities. However, some of economics' apparent laws are truths about the theory or model, not about the world; for instance, concerning the relationship between concepts (e.g. Gorton 2016). Others are too exception-ridden in actual systems or imprecise in their resulting predictions to resemble the laws of physics. The law of demand, where increasing prices decrease demand, is used as an example of this last (e.g. Gorton 2016). So, too, since economics is still in the business of describing human behaviour, the same objections to the possibility of finding general propensities would arise as elsewhere (e.g. Hausman 1994: 2-3).

Second, one might appeal to some particular exception: a regularity that is robust across background conditions and, hence, more akin to a law-like regularity. That, however, would do little to save the feasibility requirement from the following arguments. In short, one or two regularities of this kind would not suffice to answer the questions of feasibility of concern to a political philosopher, for instance, permitting us to assess proposals like socialism or a new approach to climate change.

Third, some might think that I have been overly conservative about the state of social science. One day, perhaps social science will provide law-like regularities. However, to think that social

\footnotetext{
${ }^{19}$ For one discussion, see Martin \& McIntyre 1994, introduction. As they describe it, the 'naturalistic' approach, where social science should resemble the physical sciences although it doesn't yet, is 'no longer a popular view' and to some not 'viable’ (p. xvi). F. See also Rosenberg 2015, ch.1, Gorton 2016. For this article's purposes, one could hold either view: that social science should be like physical sciences but isn't, or that it should not be.
} 
science of the future would be radically different to that of now requires making some controversial and possibly improbable assumptions to the effect that social systems are rather less complex and dependent on human actors than they appear. ${ }^{20}$ If, regardless, one did want to so idealise social science, then I suggest that political philosophers should ignore the feasibility constraint until the science of the future arrives, for reasons detailed below. Yet the physics-worship underpinning such idealisation looks unhelpful and, currently, unpopular. Social science can achieve a great deal without it. Regardless, the goal here is not to defend social science being unlike physics but, rather, to observe some widely held views that it is so. As a result, I now argue that social science is unable to provide political philosophers with an informative feasibility requirement, unless one makes controversial, and perhaps improbable, claims about the nature of social science.

\section{Against ruling out}

At first, some might be optimistic about the prospects of social science providing constraints that rule out or count against some proposals of political philosophy, for instance, from facts about human nature or the limits of institutional design. After all, infeasibility does not require something akin to the physical impossibility provided by laws of nature. Instead, feasibility is generally located somewhere between an outcome being merely possible and its being likely (Lawford-Smith 2013: 256). For instance, we do not need to show that eradicating global poverty is impossible, but only that doing so is infeasible. For that task, social science's mechanisms and non-robust exception-filled generalisations that 'if $\mathrm{P}$, under conditions $\mathrm{x}$, sometimes Q' might appear to suffice to assess feasibility.

However, it is the way in which the findings of social science fall short of being law-like that means they cannot count against, let alone rule out, the kinds of proposals that political philosophers

\footnotetext{
${ }^{20}$ Note even those who defend social sciences as more similar to physics observe the social world's complexity and variability, including the importance of unique historical facts for understanding particular cases (e.g., Machlup 1961: 174). Such claims suffice to motivate the following arguments against the informativeness of a feasibility requirement.
} 
make. They do not, in short, give us reasons to think that one proposal is feasible but not another. After making this case below, the next section addresses whether any weaker role for feasibility assessments remains. First, then, openings to articles on justice being constrained by the facts and feasibility requirements make out that we will be answering questions like 'can we get to socialism?', 'are open borders feasible?', or 'can we eradicate global poverty?'. What social science provides us with is by no means this general: its mechanisms are fragmented and partial, and it is not in the business of answering questions like that. As such, what social science provides us with may not be the right kind of content to rule out or count against the proposals that political philosophers actually make. Here, one does not have to hold that social science is never predictive or does not enable manipulation, which is disputed. Even optimists like Julian Reiss (2007) regard the manipulative power of social science to be limited and specific to mechanisms in particular social systems, such as preventing inflation within a certain kind of economy.

Second, more importantly, regardless of whether social science does deliver the right facts, it does so only against existing background conditions. This returns to the lack of robustness and context-sensitivity of social science's generalisations. These generalisations do not apply everywhere but, say, in this one specific kind of democracy bearing particular features and, even then, only sometimes: they are highly sensitive to background conditions. If you specify the conditions enough you might get relevant facts informing us as to which mechanisms could be in play or some possible strategies to reach a particular narrow goal — although, even then, there are reasons for caution over whether strategies will transfer to new contexts successfully or whether we can know in advance which mechanisms will be in play (e.g. Cartwright \& Hardie 2012; Elster 1998). But these background conditions are often precisely what is up for grabs when political philosophers propose just societies or arrangements, or principles of justice. Political philosophers suggest changes to the 
background conditions of culture, social design, institutional structure and the like. ${ }^{21}$

For example, those who propose societies without income inequalities are suggesting that we change the background conditions that might make it true now that people do need such economic incentives. ${ }^{22}$ We would need reason to think that generalisations about current behaviour in market systems are likely to hold even when the conditions on which they depend, alter. Evidence for what holds true in our market based society will not transfer so easily: the generalisations of social science are not so robust across contexts. Someone might reply that social science could change focus and start addressing what would happen under the altered background conditions that political philosophers propose. ${ }^{23}$ To reply, there likely are not any real world systems exemplifying the changes ideal theorists propose to be examined to produce such empirical findings. So, too, again, until social science did so change, then political philosophers can safely ignore a feasibility requirement.

Further, this challenge to the usefulness of social science for an informative feasibility requirement extends beyond the proposals of ideal theory to those of non-ideal theory in its various forms ${ }^{24}$ Take forms of non-ideal theory that rejects some particular ideal theory assumptions, like full compliance. Still, the resulting proposals would not keep enough of the background conditions constant for the fragmented and limited social science's regularities to hold and, still, the proposals would be too general in scope. Merely giving up one or two - or even many -idealising assumptions won't rescue a feasibility requirement.

Some might hope that non-ideal theory that addresses transitional justice, or where to go from

\footnotetext{
${ }^{21}$ This may echo Rawls' comment that finding the 'limits of the practicable' faces a problem that "the limits of the possible are not given by the actual, for we can to a greater or lesser extent change political and social institutions, and much else" (2001: 5).

${ }^{22}$ See Cohen's comments on recycling (2008).

${ }^{23}$ With thanks to a referee for this criticism.

${ }^{24}$ I follow Valentini (2012) who helpfully separates out types of non-ideal theory, distinguishing the claim that justice should be realisable from views that we should revise certain ideal theory assumptions or address 'transitional' justice.
} 
here, does better. Yet even in this case we have the same reasons to be cautious over whether judgements of feasibility can be made by drawing on social science if any significant or wide-ranging changes to the status quo are considered, as often they are. Take, for instance, proposals that we share out the costs of climate change amongst countries that have most contributed to it. That is not to say, of course, that social science couldn't play a different but useful role in accounts of non-ideal or transitional justice. For instance, they might describe the circumstances as they are such that we could know which proposals successfully addressed the issue at hand rather than, say, misunderstanding the nature of the problem. But we cannot then choose amongst the proposals with any degree of certainty on the grounds some are more feasible than others.

However, the nearer we get to choosing amongst policy proposals to be implemented in some particular country at some particular time, with the background conditions held constant and the question asked narrow, the more likely it is that an informative feasibility requirement is possible. As a consequence, some small part of non-ideal theory may escape my sceptical challenge to the usefulness of a feasibility requirement; namely, that which takes very seriously the idea that its task is addressing what to do here and now in the sense of focusing on small scale, highly local policy changes. One instance would be examining flood insurance schemes in the UK (O'Neill \& O'Neill 2012). Regardless, that looks rather unlike most of contemporary political philosophy, whether ideal or non-ideal. ${ }^{25}$

Thus, we lack the right kinds of facts to rule out or count against any of political philosophy's ideal proposals on the grounds that they are infeasible, nor near all non-ideal proposals. To deny this requires siding against commonplace views about social science, including the explanations of why social science is the way it is grounded on the very nature of social systems. Again, this argument is no criticism of social science, which may well provide robust findings in particular contexts with background conditions held fixed. But such contexts are not what political philosophers tend to care about.

\footnotetext{
${ }^{25}$ Note the exception here is narrow concrete policy proposals and not what philosophers sometimes describe as such, like equal educational opportunity.
} 
Objecting, some might say I have overlooked a social science that does tell us something less context sensitive; namely, psychology. Biases in our thinking could serve as motivational constraints, such as Miller's (2013) claim that we naturally identify with those like us or that human societies have a natural limit to their size. Such claims may tell against the feasibility of global egalitarianism for beings like us. Alternatively, perhaps our innate selfishness rules out as infeasible Carens' market socialism without economic incentives $(1981){ }^{26}$

However, the empirical grounding for such claims about psychology presenting limits on what we could achieve is, at best, shaky. Sometimes we can point to societies where things have been otherwise: societies without capitalist systems of motivation, say. Further, regardless, claims about our biases tells us a limited amount about what could be brought about were institutions different or norms changed. To support that, one might note the way in which findings of psychology experiments vary where studies are carried out on differing populations, especially, on groups other than American college students..$^{27}$ Indeed, even very fundamental seeming motivations in humans, complete with evolutionary advantages, alter. To give an example popular with proponents of cultural evolution, the average number of children women had decreased dramatically, before that could be seen as a sensible trade-off for the sake of advantages of more intensive resource investment in fewer children (e.g. Sober 1991). Individual inability then, might be overcome collectively. As a result, we may be best thinking about findings of psychology, when they are well grounded, as obstacles to work around in thinking about the best arrangement of society rather than as determining whether a proposal is feasible or not where that is intended to rule some proposals out. Surely, some might think, such obstacles tell us something about a proposal's degree of feasibility? Below, I consider such a view.

\footnotetext{
${ }^{26}$ Another possibility is cognitive limits. But I suspect that political philosophers don't violate those - or where they do, these are cases best counted as obstacles, discussed in section 4 . With thanks to an anonymous referee for pushing me to consider psychology more carefully.

${ }^{27}$ Given the reproducibility crisis in social psychology, some might be still more pessimistic over our knowledge of human nature: Open Science Collaboration 2015.
} 


\section{4. $\quad$ Against comparisons}

The facts as they are fail to rule out proposals of the kind political philosophers tend to make but instead one might claim that we can tell, at least, that some proposals are more feasible than others, and that would count in their favour. For those who reject Lawford-Smith and Gilabert's (2012) claim that feasibility can be scalar, a similar idea can be expressed as a proposal being more likely to be feasible. For instance, open borders might be less feasible (or less likely to be feasible) than expanding who counts as an asylum seeker, or raising taxes may be more feasible (or more likely to be feasible) than all being motivated to work for the benefit of the least well-off.

The findings of social science may appear helpful when making this kind of judgement. We would seek what Lawford-Smith and Gilabert (2012) term 'soft constraints': obstacles to achieving some proposal given facts about human psychology or cultural and institutional constraints, which are neither immutable nor limit what could ever be achieved. Social scientific findings look like they could provide these mutable obstacles, say, informing us about the biases found in human psychology or details about cultural organisation, given that robustness is not required. Then we could ask how many such obstacles a proposal faces. In turn, that number would provide a sense of how far the proposal is from here, in terms of how many features of current society would have to be overcome. ${ }^{28}$

The obstacles account, however, is flawed. First, without an account of the mechanisms by which one could alter these obstacles, we do not know how hard each is to overcome, which we need to know to judge feasibility even in degree. Second, counting up the number of obstacles each proposal faces to being achieved fails to capture all that matters when assessing feasibility, given that feasibility is a combination of a proposal's accessibility and its stability. Changing just one aspect of a society (overcoming one obstacle) can be less stable than more extensive alterations (overcoming many obstacles $)^{29}$. For example, creating a just welfare system while keeping the rest of a capitalist system intact might be unstable. Consider the desire of those with political lobbying power to have a

\footnotetext{
${ }^{28}$ This might align with Gilbert's dynamic feasibility (2017).

${ }^{29}$ As such, local questions of feasibility touch on global ones: what will work in a particular instance depends on the system as a whole.
} 
sufficient pool of those seeking employment and so willing to take low wages, whose influence might steadily erode improvements. This last is also the reason that we should not rely on common sense judgements about what is near or far. That some society would be very different, does not necessarily show us that over time it is less feasible than another society that is apparently closer to our own, if we only count the differences. As a result, I advise epistemic modesty over our ability to assess relative feasibility of political philosophy's proposals from counting the obstacles they face alone to the extent that it becomes a usually useless criterion for theory assessment.

One might ask, what if we added causal mechanisms in order to supplement the obstacles account? Mechanisms would inform us about how to intervene in a social system and would help to determine the weightiness of obstacles. Then we could know which proposals are more feasible than others: namely, those proposals where we have a clearer sense of the mechanisms by which they could be achieved and of how to overcome the relevant obstacles.

Yet for a mechanisms approach to be informative still requires making contested commitments within the philosophy of social science. Some doubt that social science enables prediction, manipulation or control — and whether these would even be proper aims for this kind of science. ${ }^{30}$ Again, some appeal to the features of social systems to explain why social science is best off aiming at explanation, rather than control or manipulation. Social systems are complex, unclosed systems, and it is hard to know how to control or manipulate their features or outcomes. ${ }^{31}$

Admittedly, this pessimism, while common, is by no means universal. For instance, Reiss observes that social science provides some ability to control aspects of social systems, including the successful control of inflation since the 1970s and the reduction in crime in New York under Giuliani (2007: 172). ${ }^{32}$ However, even were proponents of a feasibility requirement to take this less popular

\footnotetext{
${ }^{30}$ For a discussion, see Reiss 2007. For an example see Lawson 1997.

${ }^{31}$ Cartwright (1999) thinks the same is true for physics, outside the lab, but that does not rescue the feasibility requirement.

32 The second example is controversial, despite some evidence for the 'broken windows theory' behind it, e.g. Keizer, Lindeberg \& Steg 2008, on its shortcomings in the New York case, p. 1681.
} 
stance, they would still face parallel versions of the challenges facing the 'ruling out' conception of feasibility above. In particular, even if social science does enable successful interventions in social systems that would not provide us with a satisfactory way to rank the feasibility of the kinds of proposals that political philosophers make, given their wide ranging proposals for change. That is because the mechanisms in voting behaviour, inflation control, and the like do not much help assess the feasibility of political philosophy's proposals such as open borders or socialism: these mechanisms not only fail to provide the right content but also their operation is frequently tied to the very background conditions that the political philosopher proposes that we change.

Again, this is true not only of ideal theory's proposals but most of those of non-ideal theory too - except narrow, fine-grained policy proposals like flood insurance in the UK. Still, the lack of predictive and manipulative success of social science should make us cautious about the possibility of ranking non-ideal proposals by their feasibility, say, trying to assess the relative feasibility different approaches to tackling climate change. So, too, still the proposals of non-ideal theory largely share with ideal theory's proposals the features that make social sciences' generalisations less useful, such as altering the background conditions making them true. But that isn't to say that considering soft constraints is useless for political philosophers and especially not for non-ideal philosophers. Instead, a sense of these constraints, like what psychological biases we have and the mechanisms we could deploy to disrupt them, for instance, might give us pointers of ways to attempt to bring about change. What they don't do, however, is provide a systematic way to assess which proposals are more likely to be achieved, nor which are more likely to be stable once achieved.

\section{Conclusion: Beyond the feasibility constraint}

To conclude, social science as it actually is looks unlikely to provide us with informative limits that rule out or even count against proposals of the kind generally made by political philosophers, ideal or non-ideal. At the least, to deny this claim about its prospects is to make significant and contested commitments within the philosophy of social science. Thus, a feasibility constraint, or assessments of degrees of feasibility, have barely any practical use for political philosophers.

Does this mean that we can and should engage in utopian thinking, no longer concerned with 
whether our proposals are feasible? Of course, that would not mean that anything would go, given that there are plenty of other criteria for theory choice. However, some might take the opposite view; namely, that political philosophy and all its outlandish proposals are not left intact by social science failing to provide us with facts that could let us judge its feasibility. Instead, this article's argument shows that nearly all the proposals of political philosophy lie 'beyond human epistemic limitations' and are such that, as Wiens proposes, 'we cannot ever be reasonably confident about how to realise [them]' (2014: 302; see also Wiens 2015: 467). For some, like Wiens, if we cannot become confident of how to realise a proposal, that makes it infeasible. In the light of this article's argument, such a formulation of a feasibility constraint could be informative for political philosophers in a sense, albeit not as a way to choose amongst proposals. Instead, it would tell us to abandon the project of much of political philosophy altogether, given the current state of social science..$^{33}$

Thus, we are left with two options. We can either reject that there is any informative feasibility requirement that could rule out or otherwise let us choose between theories, or we can reject near all of the proposals that political philosophers make. Either way, the main point of this paper stands: we ought to go in search of the facts when debating feasibility. Further, political philosophers should be far more cautious when appealing to 'the facts' about what those facts are actually like, before making claims about what they can do. For that, philosophy of social science is more relevant for political philosophers than they have hitherto realised.

Yet there are also good reasons to prefer the first of these options. Even those who agree to a feasibility constraint on justice may hesitate to agree that for something to be a demand of justice it must lie within the current epistemic limits of social science. ${ }^{34}$ Indeed, it is uncommon to take whether I know if I can $\Phi$ to be a limit on whether I ought to $\Phi$ in the parallel literature within moral philosophy on the ought implies can principle. Thus, there is reason to resist Wiens' (2015)

\footnotetext{
${ }^{33}$ Wiens (2015) endorses this sort of pessimism for 'target view' theories alone. This article offers a wider ranging challenge, based on different grounds.

${ }^{34}$ This might form the basis for a parallel claim to Estlund's comment against extending an ought implies can style principle implausibly far (2014: 116).
} 
pessimism about political philosophy as standardly practiced: this is not the role that kind of epistemic constraint usually plays in thinking about feasibility. Further, the second option results in radical scepticism about nearly all of political philosophy, not solely ideal theory — a particularly demanding bullet to bite.

Third and finally, putting aside the feasibility requirement has advantages. In particular, there are other, more interesting, questions to address perhaps obscured by the way the debate over feasibility has conceptualised the role of facts in political philosophy. Our attention might turn, for instance, to more interesting aspects of the challenges of non-ideal theory and of realism to mainstream ideal political philosophy, without confusing these with accusations of infeasibility. For instance, we might ask what would it mean for a political philosophy to be 'political', or what makes that kind of engagement with the world as it is, attractive? So, too, considering the nature of the social sciences more closely promises to be fruitful for political philosophers more generally. The philosophy of science could inform political philosophers about how they ought to use the findings of economics, or politics, or other social sciences. This article demonstrates that fruitfulness through its challenge to the feasibility constraint, yet the feasibility constraint is but one of many ways political philosophers have sought to incorporate facts into their theories. In those other cases too, we may be able to draw interesting caveats and conclusions from taking the nature of the social sciences more seriously. By dismissing the interest of a feasibility requirement in this article, I hope to have cleared the ground for these more promising alternatives.

\section{References}

Carens, J. H. (1981). Equality, Moral Incentives, and the Market: An Essay in Utopian Politico-Economic Theory. University of Chicago Press.

Cartwright, N. (1999). The Dappled World: A Study of the Boundaries of Science. Cambridge University Press.

Cartwright, N. \& Hardie, J. (2012). Evidence-Based Policy: A Practical Guide to Doing it Better. Oxford University Press.

Cartwright, N. \& Montuschi, E. (2014). Philosophy of Social Science. Oxford University Press.

Cohen, G. A. (2003). Facts and principles. Philosophy \& Public Affairs, 31(3), 211-245.

Cohen, G. A. (2008). Rescuing Justice and Equality. Harvard University Press.

Connelly, K., \& Heesacker, M. (2012). Why is benevolent sexism appealing? Associations with system justification and life satisfaction. Psychology of Women Quarterly, 36 (4), 432-443. 
Elster, J. (1998). A plea for mechanisms. In Social Mechanisms: An Analytical Approach to Social Theory, eds. Peter Hedström and Richard Swedberg. Cambridge University Press.

Elster, J. Explaining Social Behaviour: More Nuts and Bolts for the Social Sciences. Cambridge University Press.

Estlund, D. (2011). Human nature and the limits (if any) of political philosophy. Philosophy \& Public Affairs, 39(3), 207-237.

Estlund, D. (2014). Utopophobia. Philosophy \& Public Affairs 42(2), 113-134.

Gheaus, A. (2013). The feasibility constraint on the concept of justice. The Philosophical Quarterly 63(2520, 445-464.

Gilabert, P, \& Lawford-Smith, H. (2012). Political feasibility: A conceptual exploration. Political Studies 60(4), 809-825.

Gilabert, P. (2017). Justice and feasibility: A dynamic approach. Political Utopias: Contemporary Debates, ed. M. Weber and K. Vallier. Oxford University Press.

Gorton, W. A. The philosophy of social science. Internet Encyclopedia of Philosophy. Available at http://www.iep.utm.edu/soc-sci/.

Hamlin, A. (2017). Feasibility four ways. Social Philosophy and Policy, 34(1), 209-231.

Hausman, D. M. (Ed.). (1994). The Philosophy of Economics: An Anthology. Cambridge University Press.

Keizer, K., Lindenberg, S., \& Steg, L. (2008). The spreading of disorder. Science, 322(5908), 1681-1685.

Kitcher, P. (2003). Science, Truth, and Democracy. Oxford University Press.

Lawford-Smith, H. (2013). Understanding political feasibility. Journal of Political Philosophy 21(3), 243-259.

Lawson, T. (1997). Economics and reality. London: Routledge

Machlup, F. (1961). Are the social sciences really inferior? Southern Economic Journal, 27(3), 173-184.

Martin, M., \& McIntyre, L. C. (1994). Readings in the Philosophy of Social Science. MIT Press.

Miller, D. (2013). Justice for Earthlings: Essays in Political Philosophy. Cambridge University Press.

Okin, S. M. (1989). Justice, Gender and the Family. Basic Books, New York.

O’Neill, J. \& O’Neill, M. (2012). Social justice and the future of flood insurance. Joseph Rowntree Foundation report. Available at https://www.jrf.org.uk/report/social-justice-and-future-flood-insurance.

Open Science Collaboration. (2015). Estimating the reproducibility of psychological science. Science, $349(6251)$, aac4716.

Rawls, J. R. (2001). Justice as Fairness: A Restatement. Harvard University Press.

Reiss, J. (2007). Do we need mechanisms in the social sciences?. Philosophy of the Social Sciences 37(2), 163184.

Rosenberg, A. (2015). Philosophy of Social Science. Westview Press

Rossi, E., \& Sleat, M. (2014). Realism in normative political theory. Philosophy Compass, 9(10), 689-701.

Sober, E. (1991). Models of cultural evolution. In Trees of Life: Essays in the Philosophy of Biology, P. Griffiths (ed.), Kluwer. pp. 477-492.

Southwood, N. (2015). The relevance of human nature. Journal of Ethics and Social Philosophy, 9, 1-8.

Southwood, N. (2016). Does "ought" imply "feasible"?. Philosophy and Public Affairs. 44 (1): 7-45.

Southwood, N., \& Wiens, D. (2016). “Actual” does not imply "feasible”. Philosophical Studies, 1-24.

Tilly, C. (2001). Mechanisms in political processes. Annual Review of Political Science, 4(1), 21-41. 
Valentini, L. (2012), Ideal vs. non-ideal theory: A conceptual map. Philosophy Compass, 7, 654-664.

Wiens, D. (2013). Demands of justice, feasible alternatives, and the need for causal analysis. Ethical Theory and Moral Practice, 16(2), 325-338.

Wiens, D. (2014). Going evaluative to save justice from feasibility-A pyrrhic victory. The Philosophical Quarterly 64(255), 301-307.

Wiens, D. (2015). Political ideals and the feasibility frontier. Economics and Philosophy 31(03), 447-477. 